\title{
APROVECHAMIENTO DE AVES EN LOS SITIOS DE LA BAHÍA PIZZULIC (ISLA ENGLEFIELD, SENO OTWAY, CHILE)
}

MARÍA JOSÉ BARRIENTOS C. ${ }^{\mathrm{a}}$

\section{RESUMEN}

Este trabajo presenta los resultados obtenidos del análisis de los conjuntos zooarqueológicos de aves de los sitios Pizzulic 2, Pizzulic 3 y Pizzulic 4, ubicados en la isla Englefield, cuyos fechados radiocarbónicos evidencian ocupaciones desde el Holoceno medio hasta el primer milenio de nuestra era. El análisis de la avifauna permitió determinar la existencia de una continuidad en la explotación y selección de aves para estos tres sitios, explotando un reducido abanico taxonómico y una selección enfocada principalmente en la Familia Phalacrocoracidae. Asimismo, la identificación de individuos juveniles en los conjuntos estudiados sugiere ocupaciones estivales. Se detectó, en los tres conjuntos, una continuidad en el procesamiento de las aves con patrones de desmembramiento y trozamiento iterativos.

PALABRAS CLAVE: zooarqueología, aprovechamiento de aves, Holoceno medio y tardío, cazadores-recolectores marinos, diversidad taxonómica.

\section{BIRD EXPLOITATION IN THE PIZZULIC BAY SITES (ENGLEFIELD ISLAND, SENO OTWAY, CHILE)}

\begin{abstract}
This paper presents the results obtained from the analysis of the zooarchaeological bird assemblages of the Pizzulic 2, Pizzulic 3 and Pizzulic 4 sites, located in the Englefield island, whose radiocarbon dates show occupations from the Middle Holocene to the first millennium of our era. The analysis of the avifauna made it possible to determine the existence of continuity in the exploitation and selection of birds for these three sites, exploiting a reduced taxonomic range and a selection focused mainly on the Phalacrocoracidae Family. Likewise, the identification of juvenile individuals in the studied suggests summer occupations. In all three sets, a continuity in the processing of the birds with iterative dismemberment and chopping patterns was detected.
\end{abstract}

KEY WORDS: Zooarchaeology, bird exploitation, middle and late Holocene, marine huntergatherers, taxonomic diversity.

a $\varangle$ mjosebarrientosc@gmail.com 


\section{INTRODUCCIÓN}

Las estrategias de subsistencia en contextos de cazadores-recolectores marinos en los sitios del estrecho de Magallanes y seno Otway se observan, en general, dominadas por una especialización en la caza marina, principalmente de presas de mayor tamaño como pinnípedos (Emperaire \& Laming, 1961; Legoupil, 1997; Legoupil et al. 2011; San Román, 2013; San Román et al. 2016), que presentan una mayor biomasa consumible y un elevado aporte de proteínas y grasas. Esta tendencia también se ha detectado en los sitios de la costa norte del canal Beagle (Schiavini, 1993; Orquera \& Piana, 1999; Estévez \& Gassiot, 2002; Piana et al. 2007). Asimismo, existirian recursos con bajo rendimiento calórico individual pero que permiten capturas masivas, tales como moluscos, peces y aves. Tal es el caso de aves gregarias (Piana et al. 2007; Tivoli, 2010a, 2010b) y algunas especies de peces demersales (Torres et al. 2020). En general, los recursos de este tipo han sido considerados como amortiguadores que le habrian dado flexibilidad al sistema cuando escaseaban otros recursos. También han sido considerados como un complemento estacional principalmente durante la época estival (Savanti, 1994; Lefèvre, 1997a; Piana et al. 2007; Moreno et al. 2009; Orquera \& Piana, 2015). Sin embargo, no sólo el comportamiento de los animales y su aporte en biomasa determinan su explotación. En este sentido, algunos estudios etnoarqueológicos muestran que las capturas masivas de algunos recursos varían según los objetivos de alimentación del grupo más que por el aporte energético que proporcionan (Lupo \& Schmitt, 2005).

En general, las principales investigaciones sobre la avifauna en los sitios del estrecho de Magallanes, el archipiélago Fueguino y la costa norte de Tierra del Fuego, señalan la importancia de este recurso en la subsistencia humana, detectándose una explotación sistemática a partir de los 6.500 años AP (Lefèvre, 1989a, 1989b, 1993-1994, 1997b, Savanti, 1994; 2010; Mameli, 2003; Tivoli, 2010a; Tivoli \& Zangrando, 2011; Lefèvre \& Laroulandie, 2014; Zangrando \& Tivoli, 2015). Particularmente, para los sitios ubicados en el seno Otway, Lefèvre (1989a) propone la existencia de una especialización en la explotación de aves desde el Holoceno medio, debido a que detecta una selectividad hacia un Género predominante (Phalacrocorax sp.) en una escala temporal amplia. Asimismo, en el seno Skyring se observa una especialización en la explotación de aves durante el Holoceno tardío (Lefèvre, 1997a; Legoupil, 2000). Dicha importancia también se encuentra documentada en estudios etnográficos en la región, aprovechándose desde sus plumas, tendones, piel, carne y huesos con fines económicos, ornamentales, simbólicos y tecnológicos (Gusinde, 1991; Emperaire, 2002; Vega, 2009).

Para este trabajo se analizaron los conjuntos avifaunísticos de los sitios Pizzulic 2, Pizzulic 3 y Pizzulic 4 (en adelante PZZ-2, PZZ-3 y PZZ4), ubicados en la bahía Pizzulic, isla Englefield. Estudios previos de estos sitios sugieren que fueron generados por grupos de tradiciones tecnológicas diferenciadas (San Román, 2013, 2016; San Román et al. 2016). Los fechados radiocarbónicos plantean tres momentos de ocupaciones que se iniciarian cerca de los ca. 6.500 años AP hasta el primer milenio de nuestra era.

El análisis que se presenta a continuación tuvo como objetivo determinar la composición taxonómica y anatómica de aves. La investigación ha incluido, entre otros aspectos, el registro de las modalidades de explotación y procesamiento de aves con la finalidad de evaluar potenciales cambios y/o continuidades en el proceso de consumo de este recurso a lo largo de la secuencia de ocupación de la bahía Pizzulic. Como complemento, se analiza la estructura taxonómica, con el objeto de cotejar si la explotación de ciertos taxa presenta o no variaciones a lo largo del tiempo.

\section{LOS SITIOS DE LA BAHÍA PIZZULIC}

La isla Englefield presenta una extensión de $10,4 \mathrm{~km}^{2}$, se ubica en el sector central del seno Otway y corresponde a la más grande de un grupo de islas e islotes próximos entre sí. Geomorfológicamente, presenta un relieve escarpado con acantilados hacia la parte sur, costas rocosas de guijarros y gravas en toda su extensión, junto a pequeñas bahías que son propicias para el asentamiento humano (Legoupil, 2013), tal como lo atestiguan los sitios emplazados en la bahía Pizzulic ubicada al noroeste de la isla (Figs. 1 y 2). 

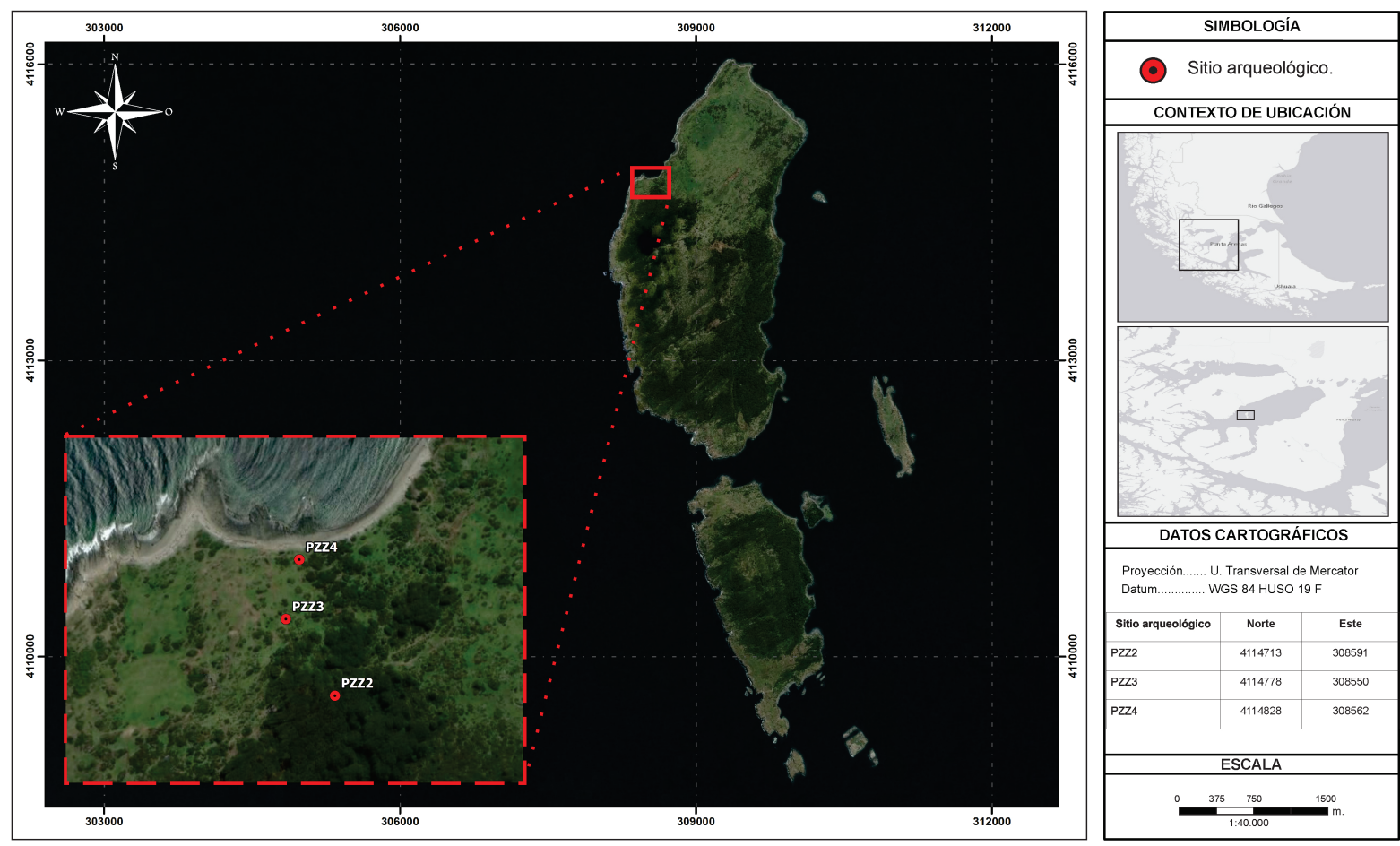

Fig. 1. Isla Englefield. Ubicación del área de estudio.

A partir de prospecciones arqueológicas realizadas en el año 2002 en la costa noroccidental de isla Englefield, se identificaron y sondearon los sitios PZZ-1, PZZ-2 (San Román et al. 2002; San Román, 2005). Adicionalmente, entre los años 2010 y 2013, se registraron los sitios PZZ-3 y PZZ-4 que fueron sondeados y posteriormente excavados.

En total se excavaron $15 \mathrm{~m}^{2}$ en cada uno de los sitios. Inicialmente en PPZ-2 se trazó una trinchera de $6 \mathrm{~m}^{2}$ de donde se extrajo es la muestra que se analiza en este trabajo (ver San Román, 2013).

Este sitio (PZZ-2) se ubica en la terraza alta, a unos $12 \mathrm{msnm}$ y corresponde a un conchero denso monocomponente de $70 \mathrm{~cm}$ de espesor, que ha sido interpretado como un campamento residencial. El análisis de los materiales recuperados de las trincheras permitió establecer la existencia de un

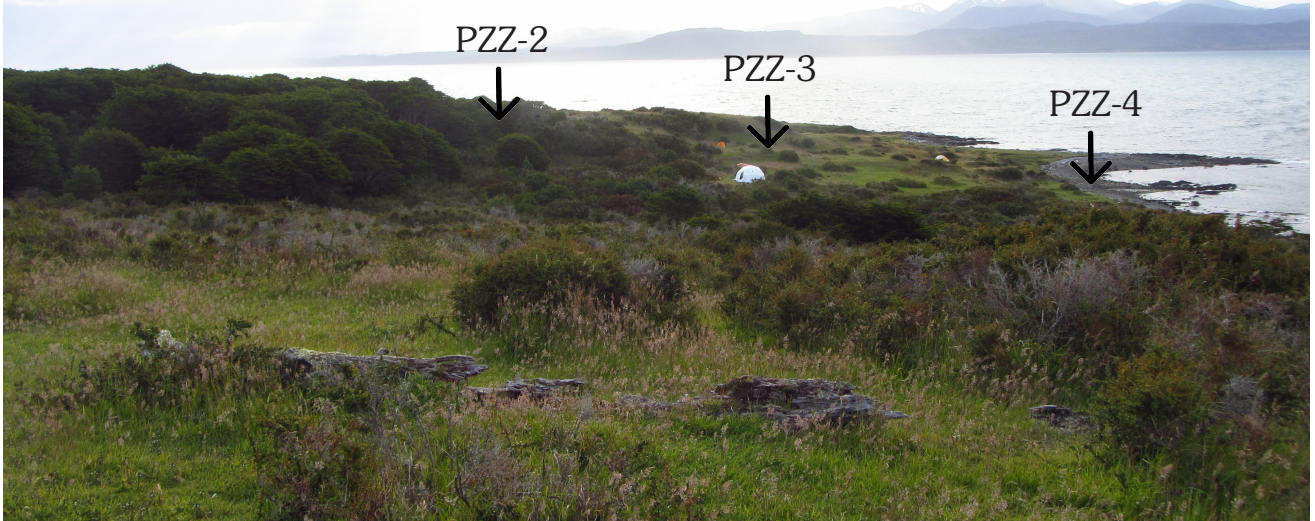

Fig. 2. Los sitios de la bahía Pizzulic en relación a las terrazas marinas en las que se ubican. Fotografía de la autora. 
importante componente arqueológico representado por un conjunto de artefactos e instrumentos diagnósticos de la tradición Englefield (San Román, 2005, 2013, 2016). PZZ-3 se emplaza en la terraza intermedia a $7 \mathrm{msnm}$, cuyo asentamiento monocomponente presenta ocupaciones esporádicas con un escaso desarrollo de conchero, el que no supera los $30 \mathrm{~cm}$ de profundidad. A partir de los conjuntos artefactuales ha sido interpretado como un campamento y taller lítico, caracterizado por escasos instrumentos y artefactos formatizados, destacando la identificación de puntas lanceoladas (San Román, 2005, 2013). Finalmente, PZZ-4 está situado en la terraza actual a $1 \mathrm{msnm}$ y corresponde a un yacimiento monocomponente que alcanza un depósito máximo de $30 \mathrm{~cm}$ de profundidad, compuesto por lentes de conchero discreto de valvas de Mytilus sp. y Nacella sp. Este sitio presenta ocupaciones domésticas bastante efímeras y una baja densidad artefactual, así como también de restos óseos de vertebrados (San Román op. cit.).

En cuanto a los tiempos de formación de los depósitos, en PZZ-2 los fechados realizados permiten establecer que se habrían formado en un lapso que no supera los 300 años, dado que los niveles próximos a la superficie fueron datados en 5.945 años AP y
5.910 años AP, y el fechado basal arrojó una fecha de 6.200 años AP (Tabla 1) (San Román, 2005, 2013, 2016). En cuanto a PZZ-3, las características del depósito y la distribución de los materiales permiten plantear que se trata de un asentamiento monocomponente, no obstante, las dos dataciones realizadas presentan fechas distantes entre sí, con una diferencia de 1.390 años AP (ver Tabla 1). Al aplicar la corrección del efecto reservorio al fechado sobre conchas, revelaría una diferencia de 1.010 años AP. Sin embargo, incluso con la corrección de fechado, ésta se contrapone con las características estratigráficas del sitio, ya que presenta un escaso desarrollo vertical lo que sugiere una formación del depósito en un espacio acotado de tiempo (San Román, 2005, 2013). Para PZZ-4, la batería de fechados plantea que el período de formación no superaría los 230 años AP (ver Tabla 1) lo que se ve apoyado por las características de la estratigrafía, ya que muestra una ocupación efímera, breve y con poco desarrollo vertical, tal vez producto de escasas estadías (San Román op. cit.).

\section{MATERIAL Y MÉTODO}

Se realizaron determinaciones anatómicas y taxonómicas para los conjuntos analizados,

Tabla 1. Fechados radiocarbónicos de los conjuntos zooarqueológicos (fechados tomados de San Román, 2005, 2013) y NISP de aves en relación a mamíferos marinos

\begin{tabular}{|c|c|c|c|c|c|c|c|c|}
\hline Sitio & $\begin{array}{c}\text { Cronología } \\
\text { (años }{ }^{14} \mathrm{C} \mathrm{AP} \text { ) } \\
\text { No calibrados }\end{array}$ & $\begin{array}{c}\text { Código } \\
\text { laboratorio }\end{array}$ & $\begin{array}{l}\text { Material } \\
\text { fechado }\end{array}$ & $\begin{array}{c}\text { Muestra analizada } \\
\text { procedencia ( }{ }^{2} \text { de } \\
\text { área excavada) }\end{array}$ & $\begin{array}{l}\text { NISP } \\
\text { aves }\end{array}$ & $\begin{array}{l}\text { Densidad } \\
\text { aves } \\
\left(\mathrm{NISP} / \mathrm{m}^{3}\right)\end{array}$ & $\begin{array}{c}\text { NISP } \\
\text { mamíferos } \\
\text { marinos }^{1}\end{array}$ & $\begin{array}{c}\text { Densidad } \\
\text { mamíferos } \\
\text { marinos } \\
\left(\mathrm{NISP} / \mathrm{m}^{3}\right)\end{array}$ \\
\hline \multirow{5}{*}{ PZZ-2 } & $5.910 \pm 30$ & GIF - 122299 & Carbón & $6 \mathrm{~m}^{2}$ trinchera & 3.892 & 926,7 & 995 & 237 \\
\hline & $5.945 \pm 45$ & $\mathrm{Ua}-21030$ & Carbón & \multirow{4}{*}{$\begin{array}{c}9 \mathrm{~m}^{2} \text { excavación } \\
\text { ampliada }^{1}\end{array}$} & \multirow{4}{*}{--} & \multirow{4}{*}{--} & \multirow{4}{*}{2.978} & \multirow{4}{*}{472,6} \\
\hline & $6.055 \pm 60$ & $\mathrm{Ua}-21031$ & Carbón & & & & & \\
\hline & $6.200 \pm 40$ & GIF - 12301 & Carbón & & & & & \\
\hline & $6.720 \pm 60$ & GIF - 12258 & Concha & & & & & \\
\hline \multirow{2}{*}{ PZZ-3 } & $3.890 \pm 40$ & BETA - 293303 & $\begin{array}{c}\text { Óseo } \\
\text { guanaco }\end{array}$ & \multirow[t]{2}{*}{$15 \mathrm{~m}^{2}$} & \multirow{2}{*}{3.232} & \multirow{2}{*}{718,2} & \multirow{2}{*}{190} & \multirow{2}{*}{42,2} \\
\hline & $5.280 \pm 65$ & GIF - 12259 & Concha & & & & & \\
\hline \multirow{4}{*}{ PZZ-4 } & $985 \pm 30$ & BETA - 293304 & Carbón & \multirow{4}{*}{$15 \mathrm{~m}^{2}$} & \multirow{4}{*}{254} & \multirow{4}{*}{56,4} & \multirow{4}{*}{18} & \multirow{4}{*}{81} \\
\hline & $960 \pm 30$ & GIF - 12300 & Carbón & & & & & \\
\hline & $1.110 \pm 35$ & GIF - 12243 & Concha & & & & & \\
\hline & $1.340 \pm 30$ & BETA - 293305 & Concha & & & & & \\
\hline
\end{tabular}

1 Para la referencia de los valores NISP mamíferos marinos ver San Román (2013). 
considerando aspectos morfológicos de los huesos a través de la consulta de claves osteológicas (Ede, 1965; Baumel \& Witmer, 1993; Cohen \& Serjeantson, 1996) y a la colección de referencia del Centro de Estudios del Hombre Austral, Instituto de la Patagonia, Universidad de Magallanes. Los restos analizados, en su mayor parte, pudieron asignarse a grupos taxonómicos mayores como Orden y Familia, salvo en algunos casos en que fueron determinados a nivel de Género y Especie. La edad representó para nuestro caso una dificultad, pues el desarrollo de los huesos para las aves se registra de manera muy temprana (Lefèvre, 1989a; Savanti, 1994; Reitz \& Wing, 2008; Serjeantson, 2009). Para el presente estudio sólo se identificó la categoría de adultos y juveniles.

Con respecto a las alteraciones que afectaron a los restos óseos se tuvieron en cuenta los distintos procesos físico-químicos y las marcas generadas por agentes naturales y culturales (Binford, 1981; Lyman, 1994; Muñoz \& Savanti, 1998; Mengoni, 1999; Mameli \& Estévez, 2004). Para la meteorización se empleó una escala específica para aves, esto radica en que su estructura ósea es diferente a otros vertebrados, en donde intervienen la densidad mineral ósea de ciertas unidades anatómicas, la neumatización y algunas diferencias en las estructuras anatómicas asociadas a distintos medios de locomoción (Muñoz \& Savanti, 1998; Mameli \& Estévez, 2004; Cruz, 2005, 2014).

En esta escala el estadio de meteorización 0 implica ausencia de alteraciones. Mientras que el estadio 1 se caracteriza por agrietamientos longitudinales cortos y poco profundos; el estadio 2 por agrietamientos destacados, quebraduras y porosidad de la superficie; el estadio 3 por agrietamientos pronunciados, descascaramientos, alisado de epífisis; y finalmente el estadio 4 por astillado, deshechos (Muñoz \& Savanti, 1998, p. 111).

Las modificaciones antrópicas incluyen: huellas de corte, termoalteración y fracturas (GiffordGonzález, 1989; Lyman, 1994; Mameli \& Estévez, 2004; Serjeantson, 2009). La termoalteración se relaciona con el grado de alteración térmica a la que podrían haber sido expuestos los restos óseos. En contextos antrópicos, no todos los huesos termoalterados responden a una actividad de consumo, también tienen relación con el descarte.
Para este estudio se complementaron las escalas propuestas por Mameli y Estévez (2004).

Con el objetivo de evaluar la variabilidad del registro zooarqueológico se emplearon parámetros como las medidas de abundancia taxonómica NISP y MNI y las medidas de abundancia relativa de partes esqueletarias MNE y MAU (Grayson, 1984; Lyman, 1994, 2008). Dada la alta fragmentación de los conjuntos, se estableció la relación NISP/MNE sólo para Phalacrocorax sp., dado que fue el taxón más representado (Lyman, 2008). Posteriormente, se realizaron análisis de estructura y diversidad para los tres conjuntos avifaunístico. La riqueza taxonómica fue estimada a través del NTAXA (Lyman, 2008, 2015), mientras que se utilizó el índice de Shannon para medir la diversidad de los conjuntos. De este modo, la equitatividad taxonómica (evenness), intenta determinar si la contribución relativa de cada taxa dentro de un conjunto es equitativa o si existen taxones dominantes y a partir de ello hacer comparaciones con otros conjuntos (Lyman, 2008; Reitz \& Wing, 2008). En este sentido, las faunas son equitativas cuando cada taxón tiene el mismo número de individuos y no lo son cuando presentan distintos números de individuos independientemente de la riqueza taxonómica. Estos valores oscilan entre 0 y 1 , en donde los valores próximos a 1 indican que los taxones se encuentran en una proporción semejante, mientras que valores más cercanos a 0 indican que hay uno o dos taxones que sobresalen cuantitativamente en el conjunto (Lyman, 2008; Reitz \& Wing, 2008). La heterogeneidad de los conjuntos, corresponde a una medición simultánea de riqueza y uniformidad taxonómica; generalmente varía entre 1,5 y 3,5 y en donde los valores más elevados se interpretan como una mayor heterogeneidad de los conjuntos (Lyman, 2008).

\section{RESULTADOS Y DISCUSIÓN}

Se analizó un total de 7.378 restos óseos de aves, distribuidos entre el sitio PZZ-2 con 3.892 (52,75\%), el sitio PZZ-3 con 3.232 (43,8\%) y el sitio PZZ-4 con 254 (3,44\%) restos óseos (Tabla 2).

El espectro taxonómico de los sitios analizados es más abundante en PZZ-2 y más reducido en PZZ-3 y PZZ-4 e incluye aves marinas, 
litorales y muy escasamente pelágicas y terrestres. Dado lo acotado del material comparativo, las determinaciones fueron posibles hasta el nivel de Familia y Género y en algunos casos llegó a nivel de Especie. El Género más frecuente en los tres sitios corresponde a Phalacrocorax sp. (cormoranes), le siguen en orden decreciente Anátidos como Tachyeres sp. (patos quetros) y

Tabla 2. Identificación taxonómica y frecuencias de restos de aves en los sitios.

\begin{tabular}{|c|c|c|c|c|c|c|c|}
\hline & \multirow{2}{*}{ TAXA } & \multicolumn{2}{|c|}{$\mathrm{PZZ}-2$} & \multicolumn{2}{|c|}{ PZZ-3 } & \multicolumn{2}{|c|}{ PZZ-4 } \\
\hline & & NISP & $\%$ & NISP & $\%$ & NISP & $\%$ \\
\hline \multirow{3}{*}{ Aves marinas pelágicas } & Procellariiformes ${ }^{2}$ & - & - & 1 & $0,03 \%$ & - & - \\
\hline & Procellariidae $e^{3}$ & 2 & $0,05 \%$ & 4 & $0,12 \%$ & - & - \\
\hline & $\begin{array}{l}\text { Thalassarche sp. } \\
\text { (Albatros) }\end{array}$ & 4 & $0,10 \%$ & - & - & - & - \\
\hline \multirow{4}{*}{ Aves de litoral } & Anatidae $^{4}$ & 69 & $1,77 \%$ & 30 & $0,92 \%$ & 9 & $3,54 \%$ \\
\hline & $\begin{array}{c}\text { Chloephaga sp. } \\
\text { (Avaturdas o gansos) }\end{array}$ & 8 & $0,21 \%$ & 4 & $0,12 \%$ & - & - \\
\hline & $\begin{array}{c}\text { Tachyeres sp. } \\
\text { (Quetro volador-quetro } \\
\text { no volador) }\end{array}$ & 73 & $1,88 \%$ & 37 & $1,14 \%$ & 5 & $1,97 \%$ \\
\hline & $\begin{array}{c}\text { Lophonetta specularioides } \\
\text { (Pato juarjual) }\end{array}$ & 9 & $0,23 \%$ & 1 & $0,03 \%$ & 2 & $0,79 \%$ \\
\hline $\begin{array}{c}\text { Aves marinas } \\
\text { buceadoras-voladoras }\end{array}$ & $\begin{array}{l}\text { Phalacrocorax sp. } \\
\text { (Cormoranes) }\end{array}$ & 2.198 & $56,47 \%$ & 707 & $21,87 \%$ & 52 & $20,47 \%$ \\
\hline \multirow{4}{*}{ Aves marinas medianas } & $\begin{array}{l}\text { Laridae }^{7} \\
\text { (Gaviotas) }\end{array}$ & 8 & $0,21 \%$ & - & - & 1 & $0,39 \%$ \\
\hline & $\begin{array}{l}\text { Stercorarius sp. } \\
\text { (Skua) }\end{array}$ & 6 & $0,15 \%$ & - & - & - & - \\
\hline & $\begin{array}{l}\text { Sterna sp. } \\
\text { (Gaviotines) }\end{array}$ & 2 & $0,05 \%$ & - & - & - & - \\
\hline & Charadriiformes $^{8}$ & 1 & $0,03 \%$ & - & - & 10 & $3,94 \%$ \\
\hline \multirow{2}{*}{ Aves terrestres } & $\begin{array}{l}\text { Tyto alba } \\
\text { (Lechuza) }\end{array}$ & - & - & - & - & 1 & $0,39 \%$ \\
\hline & $\begin{array}{l}\text { Rheidae } \\
\text { (Ñandú) }\end{array}$ & 1 & $0,03 \%$ & - & - & - & - \\
\hline $\begin{array}{c}\text { Aves marinas } \\
\text { buceadoras-no } \\
\text { voladoras }\end{array}$ & $\begin{array}{l}\text { Spheniscus magellanicus } \\
\text { (Pingüino de Magallanes) }\end{array}$ & 5 & $0,13 \%$ & 28 & $0,86 \%$ & - & - \\
\hline \multirow[t]{2}{*}{ Aves indeterminadas } & & 1.506 & $38,69 \%$ & 2.420 & $74,80 \%$ & 174 & $68,50 \%$ \\
\hline & Total & 3.892 & $100 \%$ & 3.232 & $100 \%$ & 254 & $100 \%$ \\
\hline
\end{tabular}

2 Orden que comprende a las Familias Diomedeidae, Procellariidae, Hydrobatidae y Pelecanoididae.

3 Familia que agrupa petreles y fardelas.

$4 \quad$ Familia que considera a patos, cisnes y caiquenes.

5 Anseriformes del Género Chloephaga (caiquenes) como Chloephaga picta, Ch. poliocephala, Ch. hybrida y estacionales como Ch. rubidiceps.

6 Agrupa a las tres especies de la Familia Phalacrocoracidae presentes de forma permanente en la región de Magallanes: Phalacrocorax brasilianus (yeco), Phalacrocorax magellanicus (cormorán de las rocas), Phalacrocorax [atriceps] atriceps (cormorán imperial).

7 Familia Laridae que agrupa a las principales especies presentes en la región de estudio.

8 Orden que agrupa a las Familias Haematopodidae, Stercorariidae, Laridae y Sternidae. 
Lophonetta specularioides (pato juarjual) y, en tercer lugar, Spheniscus magellanicus (pingüino de Magallanes).

El nivel de identificación taxonómica fue de $61,3 \%$ para PZZ-2, 25,2\% para PZZ3 y $31,5 \%$ para PZZ-4, estos valores para los últimos dos sitios podrían tener relación con el estadio de meteorización de los conjuntos, ya que según el cálculo de los especímenes meteorizados sobre los NISP totales, el sitio con mayor meteorización marcando desde el estadio 1 al 4, es PZZ-3 (92,2\%), le sigue PZZ-4 (82,6\%) y PZZ-2 (46,2\%) (Fig. 3).

Para evaluar si el nivel de identificabilidad de los conjuntos se vio afectado por la fragmentación, se aplicó el índice NISP/MNE. Para el Género predominante, los resultados arrojaron que Phalacrocorax sp. tiene altos índices de fracturación, sobre todo en PZZ-3 con una relación NISP/MNE $=1.39$, en PZZ-2 se observó $\mathrm{NISP} / \mathrm{MNE}=1.25$ y en $\mathrm{PZZ}-4$, NISP/MNE=1.02. En cuanto a Spheniscus magellanicus el índice muestra una baja fragmentación, lo que se debe, tanto a su escasa representación como al menor proceso de neumatización de sus huesos que los hace más resistentes (Cruz \& Savanti, 1999). En consideración a lo anterior, es importante advertir que el tamaño de la muestra influyó en los resultados porque muchos de los taxa poco representados mostraron bajos niveles de fracturación, lo que conlleva a su sobre-representación. Esto implica que un espécimen (NISP=1) puede advertir de un elemento determinado $(\mathrm{MNE}=1)$, lo que podría interpretarse como cero grado de fragmentación (Savanti, 1994). Esto se observó particularmente en PZZ-4 donde la proporción da cuenta de un conjunto poco fragmentado, cuando en realidad se debe a lo reducido del conjunto avifaunístico.

Un elemento significativo de destacar corresponde al segmento de tibiotarso de Rheidae identificado en PZZ-2, que presenta superficialmente pigmento ocre en uno de sus extremos y que por sus características pareciera ser un elemento conservado y transportado (Fig. 4). Teniendo en cuenta que Rheidae tiene una distribución continental y que junto con ello también se determinó guanaco en los conjuntos zooarqueológicos de PZZ-2, PZZ-3 (San Román, 2013, 2016), en Bahía Colorada (Legoupil, 2013) y en Englefield 1 (Emperaire \& Laming, 1961), es posible plantear varias interrogantes respecto a la movilidad de estos grupos en torno a los rangos de acción en sus desplazamientos (San Román, 2016) y a posibles actividades de intercambio entre poblaciones de diferentes localidades.

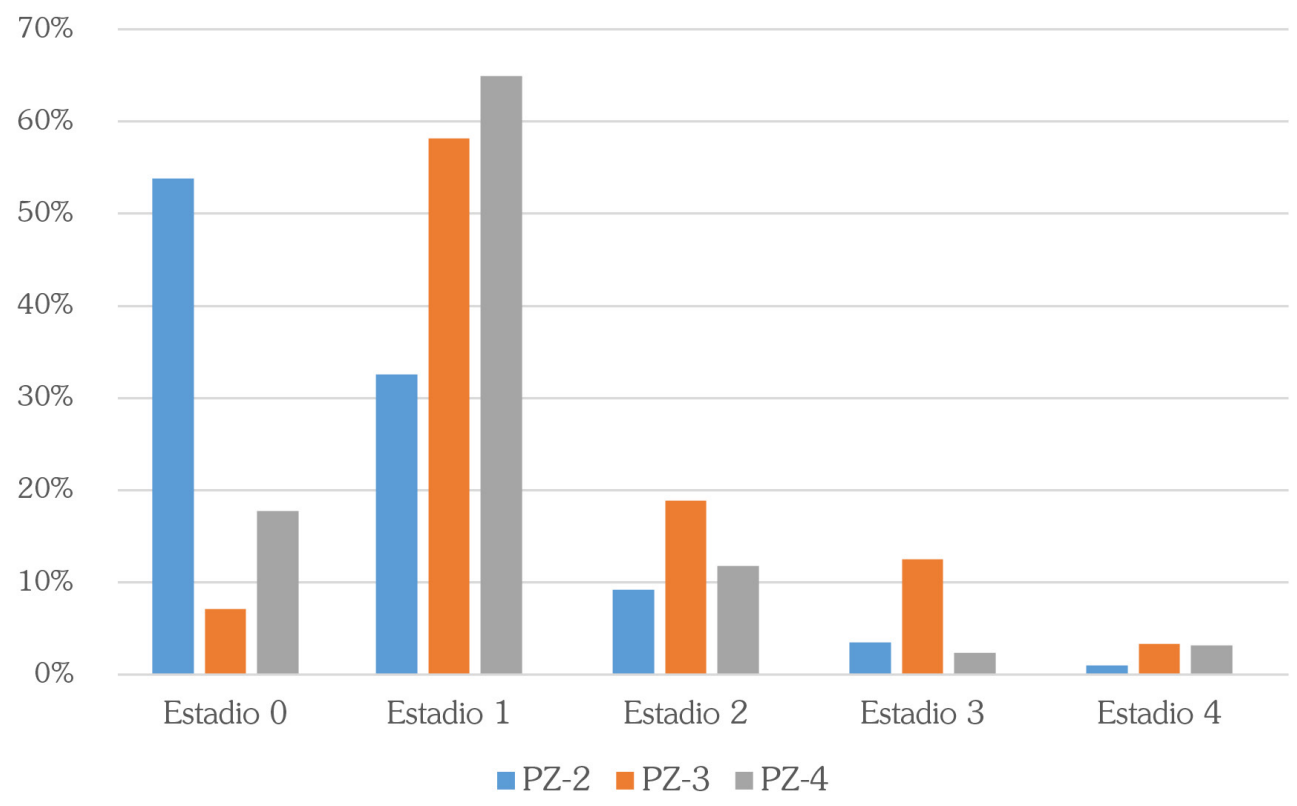

Fig. 3. Estadios de meteorización identificados para el total de los conjuntos analizados. 
En relación al MNI (Tabla 3), los cormoranes presentan la frecuencia más elevada principalmente en PZZ-2, le siguen Tachyeres sp. que representan seis individuos tanto en PZZ-2 como en PZZ-3 y tres individuos de Spheniscus magellanicus en PZZ-3. En los individuos juveniles notamos que no hay una distribución equitativa ya que las frecuencias más elevadas se registran en PZZ-2 (12,2\%) con un total de 16 individuos juveniles, de los cuales 9 (56,25\%) corresponden a Phalacrocorax sp., mientras que en PZZ-3 la frecuencia es baja $(6,8 \%)$ considerando el NISP total de aves de este sitio. En cambio, en PZZ-4 considerando el bajo NISP de aves, se puede advertir la presencia de al menos un juvenil de cormorán y uno de pato juarjual.

\section{Estructura taxonómica}

La determinación de la diversidad de los conjuntos de avifauna de los sitios en cuestión

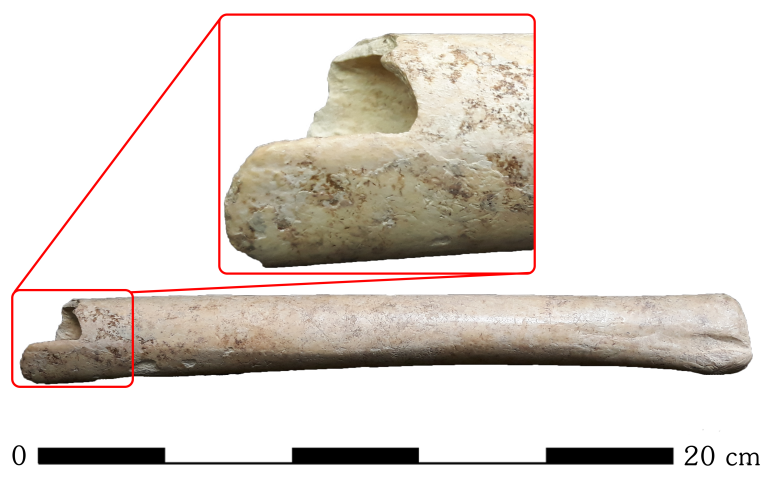

Fig. 4. Segmento de tibiotarso de Rheidae con pigmento ocre y pulimento en borde.

se realizó a partir de la estimación de la riqueza (NTAXA) y de los índices equitatividad (e) y heterogeneidad $(h)$ taxonómica (Lyman, 2008; Reitz \& Wing, 2008).

Para Lyman (2015) habría una relación causal entre el tamaño de la muestra y NTAXA,

Tabla 3. MNI adultos y juveniles de los restos óseos de aves taxonómicamente determinados.

\begin{tabular}{|c|c|c|c|c|c|c|c|c|c|c|c|c|}
\hline \multirow{3}{*}{ Taxa } & \multicolumn{4}{|c|}{ PZZ-2 } & \multicolumn{4}{|c|}{ PZZ-3 } & \multicolumn{4}{|c|}{ PZZ-4 } \\
\hline & \multicolumn{2}{|c|}{ Adulto } & \multicolumn{2}{|c|}{ Juvenil } & \multicolumn{2}{|c|}{ Adulto } & \multicolumn{2}{|c|}{ Juvenil } & \multicolumn{2}{|c|}{ Adulto } & \multicolumn{2}{|c|}{ Juvenil } \\
\hline & MNI & $\%$ & MNI & $\%$ & MNI & $\%$ & MNI & $\%$ & MNI & $\%$ & MNI & $\%$ \\
\hline Charadriiformes & 1 & 0,76 & & & & & & & 2 & 15,38 & & \\
\hline Procellariiformes & & & & & 1 & 1,37 & & & & & & \\
\hline Procellariidae & 1 & 0,76 & & & 2 & 2,74 & & & & & & \\
\hline Rheidae & 1 & 0,76 & & & & & & & & & & \\
\hline Laridae & 3 & 2,29 & 1 & 6,25 & & & & & 1 & 7,69 & & \\
\hline Anatidae & 12 & 9,16 & 4 & 25 & 5 & 6,85 & & & 2 & 15,38 & & \\
\hline Chloephaga sp. & 3 & 2,29 & & & 1 & 1,37 & & & & & & \\
\hline Stercorarius sp. & 2 & 1,53 & & & & & & & & & & \\
\hline Sterna sp. & 1 & 0,76 & & & & & & & & & & \\
\hline Thalassarche sp. & 1 & 0,76 & & & & & & & & & & \\
\hline Phalacrocorax sp. & 95 & 72,52 & 9 & 56,25 & 54 & 73,97 & 5 & 100 & 4 & 30,77 & 1 & 50 \\
\hline Tachyeres sp. & 6 & 4,58 & 1 & 6,25 & 6 & 8,22 & & & 2 & 15,38 & & \\
\hline $\begin{array}{l}\text { Lophonetta } \\
\text { specularioides }\end{array}$ & 4 & 3,05 & 1 & 6,25 & 1 & 1,37 & & & 1 & 7,69 & 1 & 50 \\
\hline $\begin{array}{l}\text { Spheniscus } \\
\text { magellanicus }\end{array}$ & 1 & 0,76 & & & 3 & 4,11 & & & & & & \\
\hline Tyto alba & & & & & & & & & 1 & 7,69 & & \\
\hline Total & 131 & $100 \%$ & 16 & $100 \%$ & 73 & $100 \%$ & 5 & $100 \%$ & 13 & $100 \%$ & 2 & $100 \%$ \\
\hline
\end{tabular}


es decir, que a mayor cantidad de restos óseos mayor deberían ser los taxa identificados. Sin embargo, al desplegar la información en un diagrama de dispersión (Fig. 5) notamos que PZZ-2 el sitio con mayor NISP, pero con una superficie menor muestreada, tendría una mayor riqueza taxonómica que PZZ-3 y PZZ-4. Del mismo modo, al comparar los valores de NISP/ NTAXA (Tabla 4) no se observa una correlación para los conjuntos analizados, ya que pareciera ser que estos valores estarían distorsionados por una probable contaminación tafonómica del depósito y que tendría como consecuencia variaciones en la riqueza taxonómica en los distintos conjuntos. Al respecto consideramos como taxa intrusivos a Stercorarius sp. en PZZ-2, en PZZ-3 a Lophonetta specularioides y en PZZ-4 a Laridae y Tyto alba.

Para el indice de equitatividad (evenness) aplicado para los tres conjuntos de avifauna (Fig. 6), se observan valores cercanos a 0 para el sitio del período Temprano (PZZ-2) e Intermedio (PZZ3), asociados a la dominancia de Phalacrocorax

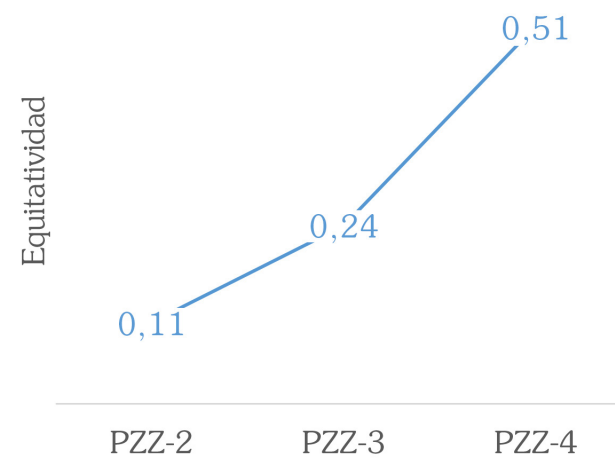

Fig. 6. Equitatividad para los tres conjuntos.

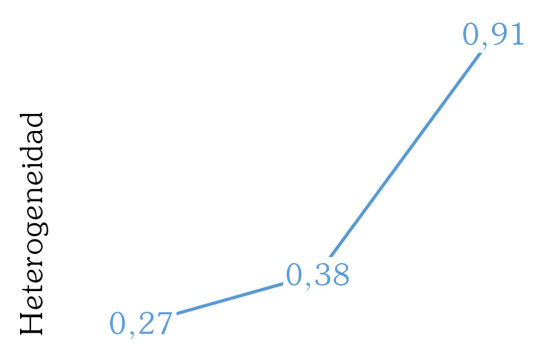

$$
\text { PZZ-2 PZZ-3 PZZ-4 }
$$

Fig. 7. Valores de Heterogeneidad.
Tabla 4. Riqueza taxonómica.

\begin{tabular}{cccccc}
\hline Sitios & Área m & NISP total & NTAXA & $h$ & $e$ \\
\hline PZZ-2 & $6 \mathrm{~m}^{2}$ & 3.892 & 11 & 0,271 & 0,11 \\
PZZ-3 & $15 \mathrm{~m}^{2}$ & 3.232 & 5 & 0,386 & 0,24 \\
PZZ-4 & $15 \mathrm{~m}^{2}$ & 254 & 6 & 0,911 & 0,51 \\
\hline
\end{tabular}

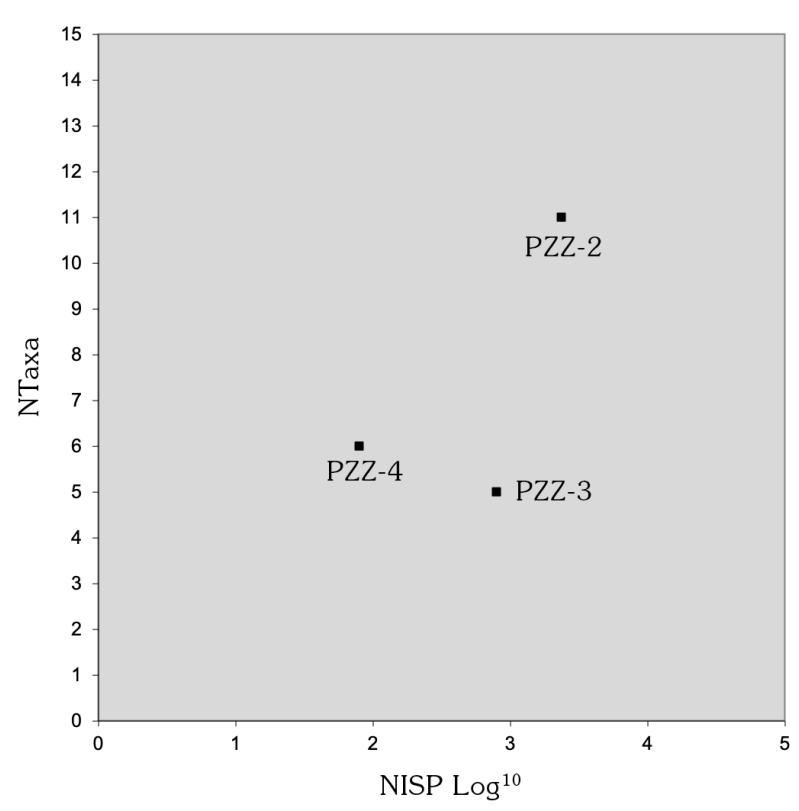

Fig. 5. Diagrama de dispersión taxonómica de los tres conjuntos analizados, considerando NTAXA y NISP.

sp. en ambos conjuntos, mientras que el índice de Heterogeneidad (Fig. 7) muestra una distribución desproporcional de los taxa de estos dos conjuntos. En el período Tardío (PZZ-4), si bien se observa una mayor representación de un taxón, también se aprecia un conjunto con una distribución más pareja en la abundancia de los taxa.

\section{La selección de aves}

Diversos estudios desarrollados en la región (Savanti, 1994; Lefèvre, 1997a; Mameli, 2003; Tivoli, 2010a, 2012) mencionan que las aves serian un recurso capturado de manera constante, pero que habría capturas intensivas durante la época estival considerando la etología de las aves gregarias durante este período, conjetura que se vería reforzada por la identificación de pichones y juveniles. 
Respecto a la estacionalidad, se registraron individuos juveniles en los tres sitios, lo que permite plantear posibles capturas esporádicas en las colonias de anidación durante el verano y comienzo del otoño. Para cormoranes, los más predominantes en los tres sitios, el período reproductivo comienza con la postura de huevos entre octubre y noviembre y que son incubados por alrededor de un mes; por lo que es posible encontrar polluelos desde noviembre hasta enero. En síntesis, la identificación de juveniles nos señala que al menos hubo ocupaciones durante algún momento del verano austral desde mediados de noviembre y posiblemente a comienzos del otoño hacia fines de marzo-abril. Esto se condice con los resultados de los análisis esclerocnológicos sobre ictiofauna (Salilota australis) para el sitio PZZ-2, que señalan capturas entre el verano y el otoño para esta especie (Torres et al. 2020).

En relación a la representación de especies, para los sitios de la bahía Pizzulic el abanico de taxa explotados es bastante reducido, si consideramos que en la actualidad existe una abundante diversidad de especies de aves residentes en la isla y en el seno Otway (GEA-UMAG, 2008). Sólo en PZZ-2 la diversidad taxonómica es mayor en comparación con los otros dos sitios (Tabla 4). Respecto a los taxa más abundantes, el espectro se observa acotado a especies de ámbito marino-litoral, las que en la actualidad son posibles de apreciar en abundancia y anidando en las costas de isla Englefield, tales como especies de la Familia Phalacrocoricidae y Anatidae. Son aves que presentan comportamientos gregarios o se agrupan en parejas, son residentes y nidificantes, tienen conductas reproductivas estables y previsibles y se agrupan en colonias de agregación durante todo el año.

A partir de los valores nutricionales en aporte energético planteados por Schiavini (1993) y los datos aportados por Tivoli (2010b) para aves, las Familias y Géneros que presentan mayores aportes en kilocalorías por individuo son Spheniscidae (2.880 kcal), Chloephaga sp. (2.460 kcal), Diomedeidae (2.030 kcal), Phalacrocoracidae (1.500 kcal), Laridae (710 kcal) y Procellariidae (400 kcal). Sin embargo, en los sitios de la bahía Pizzulic la representación taxonómica se aprecia que en orden decreciente Phalacrocorax sp. es la especie que predomina en los tres sitios con una mayor frecuencia en PZZ-2. La segunda categoría taxonómica corresponde a Tachyeres sp., Chloephaga sp. y Lophonetta specularioides de la Familia Anatidae. Son aves que nidifican y residen de forma permanente en el litoral de isla Englefield y siempre están en parejas o en pequeños grupos. No obstante, pese a que son fáciles de capturar pues en tierra no son muy hábiles (Emperaire, 2002; Vega, 2009), no están representadas en abundancia en los conjuntos zooarqueológicos de estos sitios. En tercer lugar, se identificó pingüino de Magallanes, destacando el registro exclusivo de adultos, con tres individuos en PZZ-3 y uno en PZZ-2. Estas aves son filopátricas, es decir, tienen la tendencia a volver a su colonia de nacimiento una vez comenzada la época reproductiva durante primavera-verano (Cruz, 2001; Tivoli, 2014). Gusinde (1991) menciona que la captura del pingüino se realizaba en tierra donde son menos ágiles durante la primavera, cuando están empollando sus huevos; la técnica empleada es acorralarlos hasta alcanzarlos y posteriormente matarlos con un garrote. Sin embargo, es probable que su presencia en los sitios responda a una caza oportunista.

Planteamos la posibilidad de que la selección de aves por parte de los grupos humanos que habitaron los asentamientos estudiados es concomitante con las características etológicas y su disponibilidad en el entorno. Se debe aceptar que las diferentes especies acarrean costos de captura muy desiguales, probablemente, debido a la abundancia en el ambiente y/o a la dificultad en la accesibilidad a los hábitats. Sin duda en el proceso de selección de los recursos, más allá de los costos/beneficios nutricionales y logísticos, hay ciertos criterios que no son posibles de cuantificar arqueológicamente, tales como el sabor y valorización social, elementos que tienen directa incidencia en las decisiones económicas de lo consumido por los grupos humanos (Estévez \& Gassiot, 2002; Zangrando, 2009; García Moreno, 2010).

Desde la etnografía cabe mencionar que, según Gusinde (1991), habrían existido reparos respecto al consumo de ciertas especies; por ejemplo, menciona que no consumen ninguna de las aves de rapiña ni gaviotas presentes en la zona, pues las consideran "pájaros sucios", tampoco consumen aves muy pequeñas debido a que 
ofrecen poco aporte cárnico ni aves viejas. A partir de lo anterior, es probable sostener que no todas las especies identificadas hayan sido consumidas, tal es el caso de Tyto alba y Laridae en PZZ-4 y Stercorarius sp. en PZZ-2, cuyo aporte y escasa representación anatómica en el registro de los sitios analizados podría ser debido a factores tafonómicos. De ser antrópicos, podrían corresponder a una estrategia oportunista de captura de aves solitarias y/o disponibles ocasionalmente, aunque tampoco debiera descartarse la posibilidad de una recolección aleatoria de aquellos restos óseos, como podría ser el caso de Lophonetta specularioides en PZZ-3.

Estrategias de explotación y procesamiento de aves en los sitios de la bahía Pizzulic

Debido a que son animales de menor tamaño, el aprovechamiento de las presas supone transporte completo a los asentamientos donde son desmembrados. Esto se refleja en el alto porcentaje de restosóseos sin huellas de corte de procesamiento ycon una tendencia general a una completa representación de los esqueletos (\%MAU). Principalmente en PZZ2 y PZZ-3, se observa una repartición pareja desde el cráneo a las vértebras caudales. En PZZ-4 la representación de los esqueletos no es completa, esto puede deberse a factores tafonómicos de preservación de los restos más frágiles y/o a la fragmentación de los restos óseos que no permite identificarlos, más que a una pauta económica de selección de segmentos para consumo (Fig. 8).
Tanto para cormorán como para anátidos, vemos que está representado casi todo el esqueleto, pero principalmente las frecuencias son mayores para las partes de más alto rendimiento económico, tales como el pecho y los muslos, las que además se encuentran menos fragmentadas, mientras que las de menor rinde (cintura pélvica y esqueleto axial) son, asimismo, las menos preservadas y más frágiles (Fig. 9). Estas frecuencias podrían tener relación con las pautas de trozamiento y descarte. Además, observamos una alta completitud de restos óseos de pingüino, ya que por sus características óseas se fragmentan menos y su identificación taxonómica es más fácil porque presentan características únicas.

En los conjuntos analizados se aprecia una baja incidencia de huellas relacionadas con corte, fracturas y termoalteración, ello puede tener relación con las técnicas de procesamiento y consumo. La baja frecuencia de marcas de procesamiento también es coherente con la información procedente de las fuentes etnográficas, ya que mencionan que las aves eran desmembradas sin utilizar elementos cortantes y luego expuestas completas, directamente al fuego (Gusinde, 1991).

En PZZ-4 el 1,6\% $(n=4)$ presentó huellas de corte de tipo longitudinales paralelas al eje del hueso y sólo fueron identificadas en coracoides. En PZZ-3 el 1,2\% $(n=40)$ presentó huellas de corte, registradas en la cintura escapular, extremidades anteriores y posteriores y escasamente en el esqueleto axial. Se aprecia un predominio de huellas longitudinales y transversales en húmeros,

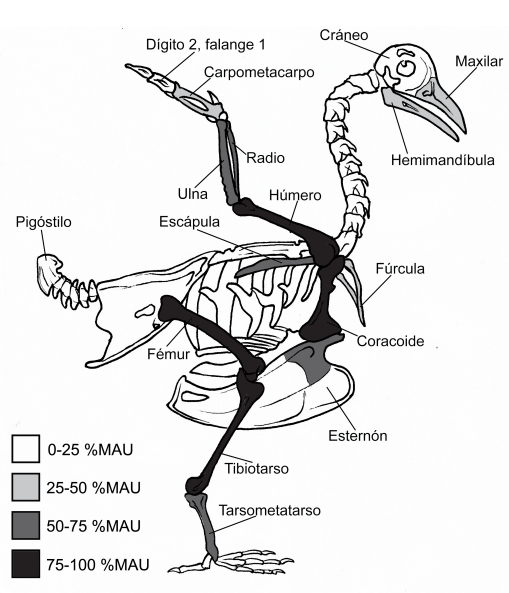

PZZ-2

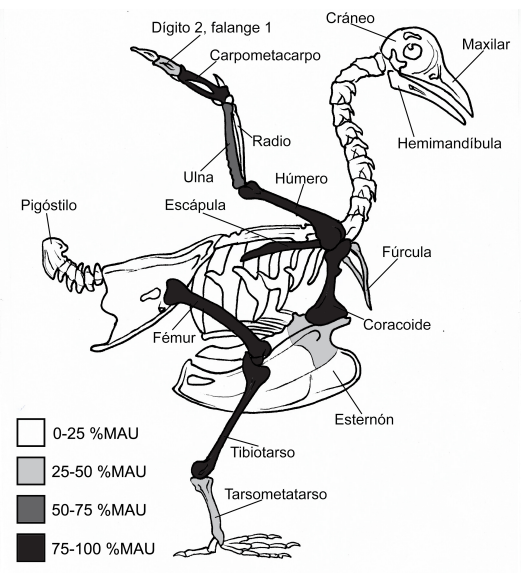

PZZ-3

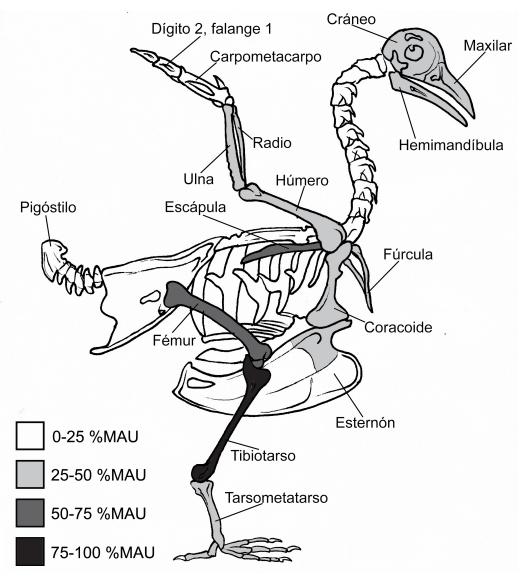

PZZ-4

Fig. 8. Representación \%MAU de los tres sitios considerando sólo los elementos taxonómicamente determinados. 


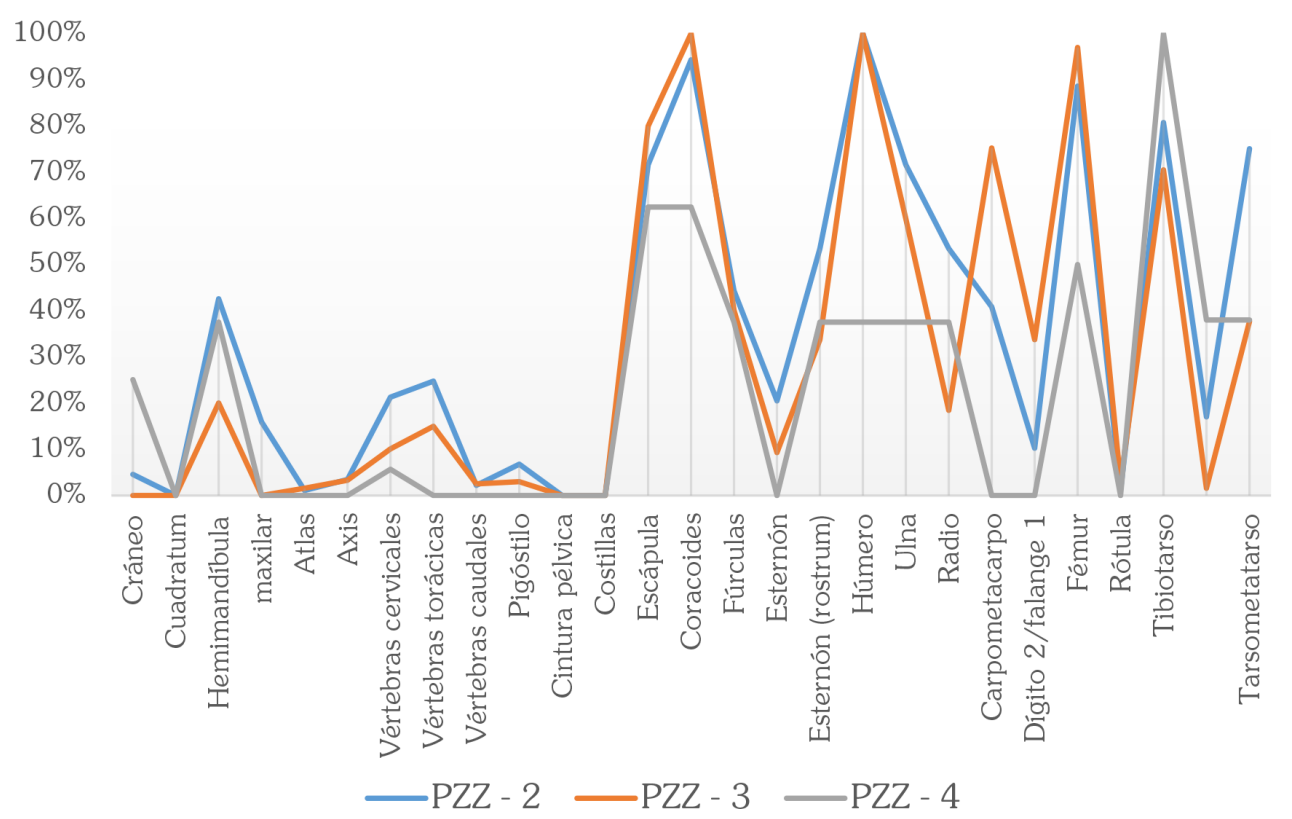

Fig. 9. Índice \%MAU de Phalacrocorax sp. de los tres sitios.

escápulas, pero sobre todo en fémures. Para PZZ2 un $2,1 \%(n=83)$ presentó huellas de corte que se ubican sobre todo en la cintura escapular, en las extremidades anteriores y posteriores (Fig. 10). Cabe destacar que Procellariiformes $(\mathrm{NISP}=1)$ presentó huellas de corte.

En general, se identificaron patrones de procesamiento en sectores con mayor rendimiento económico, lo que señala que el trozamiento se produce en el área del pecho que tiene una mayor concentración de carne y en la desarticulación del húmero del coracoides y así acceder a la carne adherida en clavículas y esternón. Particularmente en PZZ-2 se observaron patrones de procesamiento que son importantes de destacar ya que además son considerablemente más abundantes en

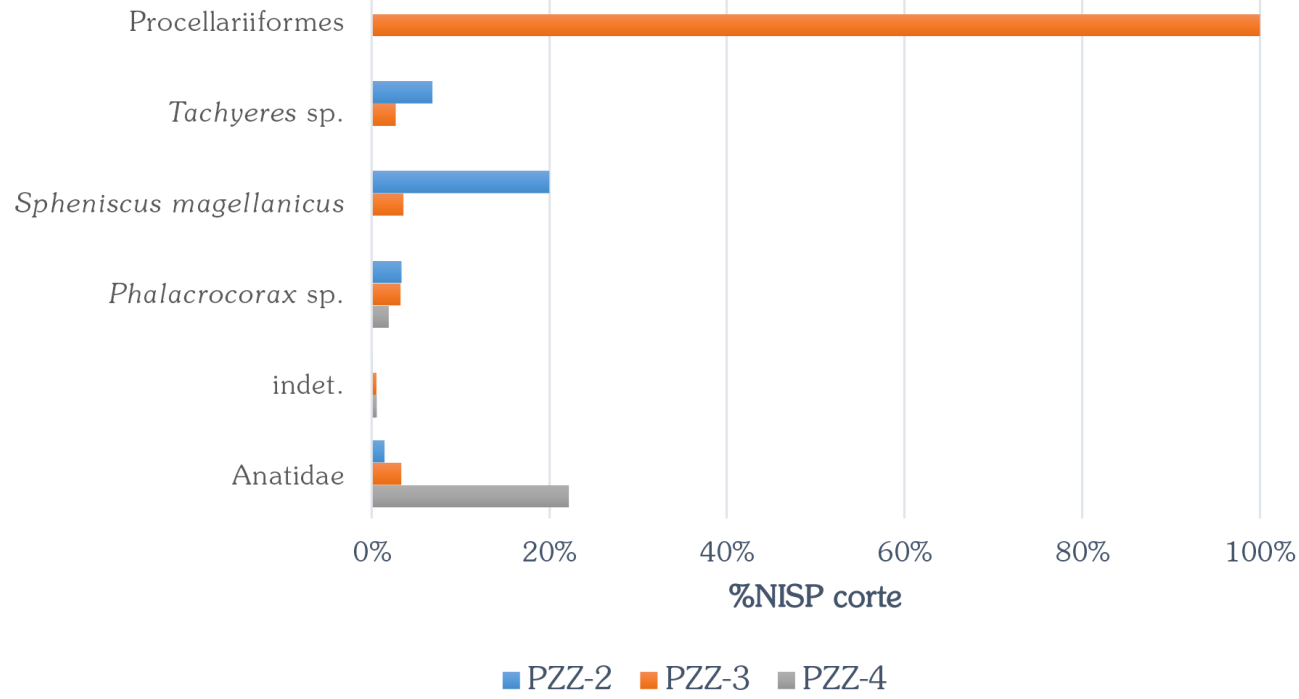

Fig. 10. \%NISP corte considerando los tres sitios. 
comparación con PZZ-3 y PZZ-4. Los húmeros son las unidades anatómicas que presentan mayor proporción de huellas longitudinales y paralelas al eje del hueso, las que se concentran exclusivamente en la cresta deltóidea (Fig. 11). Este patrón también fue identificado en individuos juveniles. En las clavículas se identificaron huellas de corte transversales ubicadas en el segmento proximal, particularmente en el proceso acromial. Los coracoides presentan la mayor frecuencia de huellas, ubicadas en el segmento proximal entre la faceta para la articulación con el húmero y la articulación con la escápula (Fig. 12). Muchas de las escápulas presentaron huellas de corte transversales paralelas entre sí, las que se ubican particularmente en la metáfisis proximal y/o concentradas en la epífisis proximal en la base del acromion.

En cuanto al patrón de aprovechamiento en las extremidades posteriores, en fémures y tibiotarsos se registraron huellas en las epífisis, principalmente en cóndilos (Fig. 13). Se aprecian algunas huellas diagonales aisladas en la diáfisis y otras concentradas en segmento medial y proximal. En el caso de los tibiotarsos observamos huellas transversales cortas y profundas ubicadas entre la metáfisis y epífisis distal. Las huellas identificadas en las extremidades posteriores podrían tener relación con la desarticulación del muslo en unidades menores (Lefèvre, 1989a; Mameli \& Estévez, 2004). Esto se condice con la presencia de marcas de exposición al fuego de estas unidades anatómicas.

En los tres conjuntos se identificaron en baja frecuencia huellas de corte en vértebras, no obstante, éstas fueron determinadas, principalmente, en cervicales y torácicas, lo que podría estar relacionado con el fraccionamiento del ave en más de una porción. Taxonómicamente
1.

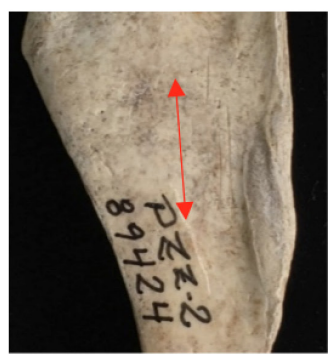

Adulto

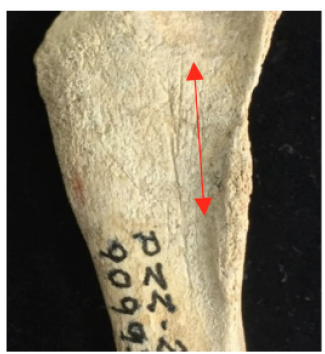

Juvenil
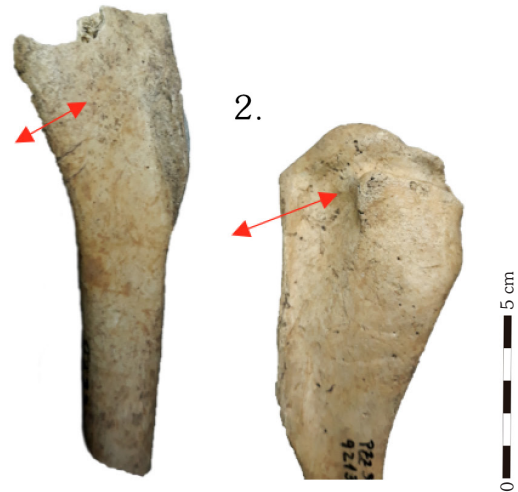

Fig. 11. Huellas de corte en húmeros. 1. PZZ-2 y 2. PZZ-3.

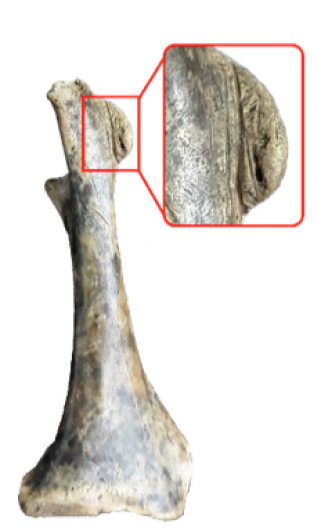

1.

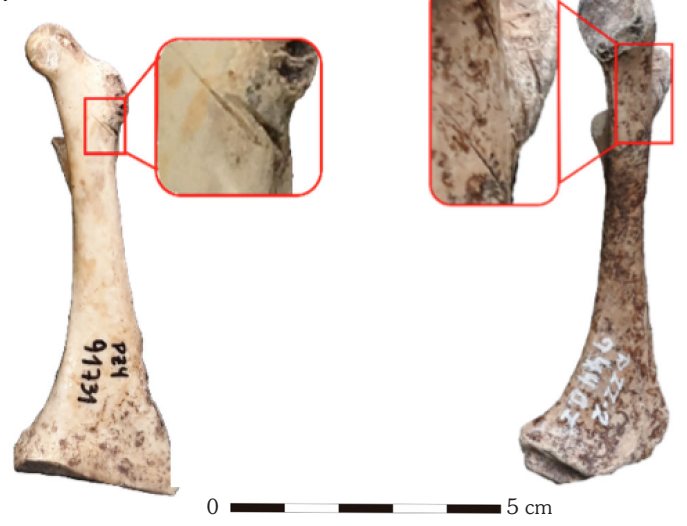

2.

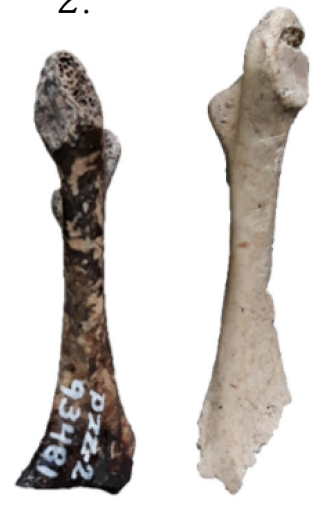

Fig. 12. Huellas de corte en coracoides. 1. PZZ-4 y 2. PZZ-2. 

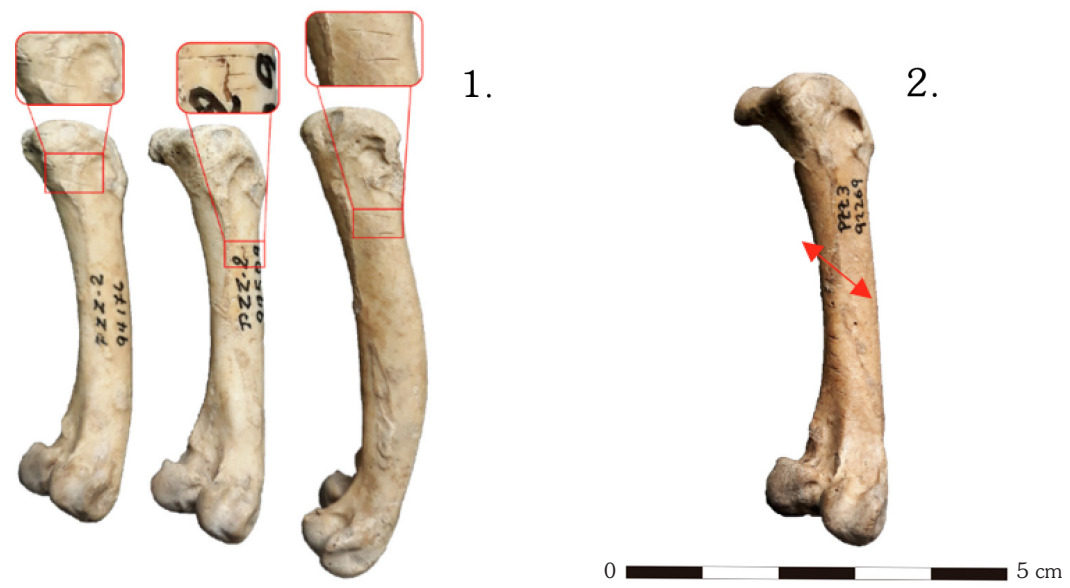

Fig. 13. Huellas de corte en proximal de fémur. 1. PZZ-2 y 2. PZZ-3.

se identificaron en cormoranes, patos quetros y anátidos indeterminados. Generalmente, las huellas de procesamiento en las extremidades anteriores se asocian a actividades de carnicería como filetear, desarticular o desmembrar y desplumar la presa (Lefèvre, 1989a; Mameli \& Estévez, 2004). Sin embargo, llama la atención la baja a nula proporción de huellas de corte en el extremo del ala, principalmente en radios y ulnas, teniendo en consideración que etnográficamente (Bridges, 1952; Gusinde, 1991; Chapman, 2002) hay registro del uso para fines ornamentales y rituales de plumas, por lo que a partir de esto sería esperable encontrar huellas en radios y ulnas donde se ubican las plumas de contorno, muy usadas para dichos fines.

Por otro lado, restos óseos termoalterados fueron registrados en baja frecuencia en los tres conjuntos. Se identificó quemado parcial en epífisis y ocasionalmente en diáfisis. Este tipo de quemadura se asocia a una exposición al fuego cuando aún la porción ósea presenta tejido. Cuando observamos restos completamente quemados podría ser indicativo de un descarte arrojándolo directo al fuego o de alguna actividad posterior, como una incineración (GiffordGonzález, 1989). Según las fuentes etnográficas, las presas se cocinaban directamente por exposición sobre el fuego. A algunas aves antes de cocinarlas les cortaban la cabeza, les abrian el vientre y les sacaban las entrañas, desechando todos los restos. Gusinde (1991) y Emperaire
(2002) sostienen que gustan de comerlos casi crudos. Estos datos cobran sentido si consideramos las bajas frecuencias de restos quemados en distintos grados, probablemente las marcas de termoalteración en epífisis estén relacionadas con porciones que quedaron expuestas al fuego mientras que las diáfisis contienen la carne y/o plantean la posibilidad de una cocción parcial de las porciones extraídas. También se identificaron vértebras quemadas completas y calcinadas, lo que podría vincularse con el descarte de esos segmentos en algunas de las etapas del consumo. En los tres sitios predominaron las marcas de quemado en los huesos que componen el muslo: fémures y tibiotarsos presentaron el predominio de quemado parcial y/o completamente. Tanto los fémures como los tibiotarsos se ubican en segmentos del ave que presentan un alto rendimiento económico con un alto aporte cárnico, por lo que apreciar marcas de quemado parcial indica que éstas unidades anatómicas fueron posiblemente asadas cuando aun tenían carne adherida.

Se identificaron fracturas en hueso fresco y que podrían tener relación con actividades culinarias, sin embargo, ninguna pudo ser atribuida a causas antrópicas producto del consumo. Waselkov (1987) plantea que como la mayoría de las aves no tiene médula, esto permite que conserven su integridad ya que los huesos no serían fragmentados intencionalmente para extraerla. En este contexto, las fracturas identificadas tendrían un origen post- 
depositacional, aunque se detectó una situación peculiar con las ulnas. En los tres conjuntos se registran en abundancia y muchas de ellas se encuentran fracturadas en una o en ambas epífisis, lo que no parece tener relación con el aprovechamiento del ala, dado que además presentan escasa presencia de huellas de corte y tampoco se encuentran quemadas. No obstante, este fenómeno ya había sido advertido por Lefèvre (1989a); quien planteó que dicho fenómeno tendría relación con el proceso de formación del hueso, dado que se desarrollarían desde la diáfisis hasta la epífisis, por ende, estos extremos serían más frágiles y fáciles de fracturar. Posteriormente Lefèvre \& Pasquet (1994) sostienen que este tipo de fracturas podrían estar relacionadas con el consumo de los extremos articulares.

\section{CONSIDERACIONES FINALES}

El principal objetivo de este estudio fue reconstruir las estrategias de aprovechamiento $y$ procesamiento de aves a lo largo de la secuencia de ocupación de cazadores-recolectores marinos en la bahía Pizzulic. La caracterización de los conjuntos avifaunísticos de los sitios PZZ-2, PZZ-3 y PZZ-4 permitió determinar que en el repertorio de aves explotadas prima la Familia Phalacrocoracidae, seguido de varias clases de anátidos (Tachyeres sp. y Lophonetta specularioides) y finalmente Spheniscus magellanicus. Los índices de heterogeneidad $y$ equitatividad mostraron que para momentos iniciales e intermedios de la ocupación humana de la bahía (PZZ-2 y PZZ-3) los conjuntos estuvieron dominados por la explotación de Phalacrocoracidae, con una contribución significativamente menor de otros taxa en los respectivos conjuntos. Para momentos finales de la ocupación (PZZ-4), si bien continuó la preponderancia en la captura y consumo de cormoranes, la importancia relativa de taxones secundarios alcanzó valores mayores, mostrando una tendencia hacia una mayor uniformidad y heterogeneidad, condicionada por un aumento en el aporte de otros taxa para dicho conjunto. Estos índices aportaron a la discusión, sin embargo, no son concluyentes ya que su empleo sólo desde las aves es un poco arriesgado, debiendo integrarse otros grupos taxonómicos para poder evaluar en conjunto las estrategias de subsistencia de la bahía Pizzulic. Las principales diferencias detectadas respecto a los conjuntos se observan esencialmente en la riqueza taxonómica, mayor en el período temprano (PZZ-2). Dicho fenómeno podría ser explicado a través de la fragmentación de los restos óseos y el grado de meteorización (elevados en PZZ-3 y PZZ-4), ya que el grado de modificación dificultó la identificación taxonómica.

Existen varios factores que podrían haber incidido en el aprovisionamiento de aves en la isla Englefield, fundamentados desde el conocimiento de la estacionalidad de los recursos, las características etológicas y la disponibilidad en el entorno. En este sentido, las colonias de aves constituyen recursos altamente productivos pues permiten aprovisionamientos durante todo el año, y además masivos y sistemáticos en primavera para la recolección de huevos y en verano para la captura de polluelos (Lefèvre, 1997a; Legoupil, 2000). La Familia Phalacrocoracidae alcanza su mayor representatividad en PZZ-2 (95\%) y en PZZ$3(91 \%)$, pareciera ser que el factor preponderante en su selección habría sido la ubicuidad de este recurso ya que implicaría menores costos de búsqueda y procesamiento, si consideramos la posibilidad de la existencia de una o más colonias en las cercanías de la isla. Esto tiene asidero cuando comparamos la representación taxonómica en los sitios del seno Otway.

La predominancia en la selección de los cormoranes en los sitios analizados permite plantear que éstos han sido las aves más abundantes y conspicuas del área durante buena parte del Holoceno, pasando a ser una especie fundamental para la subsistencia de estas poblaciones de cazadoresrecolectores marinos (Lefèvre, 2010; Zangrando \& Tivoli, 2015).

El aprovechamiento para la subsistencia sugiere un patrón recurrente en los conjuntos estudiados. Las características de las huellas de corte, aunque escasas, permiten plantear la posibilidad de patrones de desmembramiento del esqueleto, esencialmente de la cintura escapular para la extracción de carne y en las extremidades anteriores y posteriores para la desarticulación de la carcasa. Junto con ello, en los restos termoalterados, se pudo observar un predominio del 
quemado parcial en epífisis de húmeros y fémures, lo que sugiere la posibilidad de una cocción parcial de las porciones extraídas. Por otro lado, el \%MAU señala la representación de especímenes completos avalando que fueron ingresados enteros al sitio, pues dado su tamaño permiten la transportabilidad de más de un espécimen a la vez. Esto último tiene correlato en la información etnográfica, en donde se señalan partidas de capturas masivas de aves, variando según la época del año y el sector donde estuviesen (Webster, 1834 en Orquera \& Piana, 2015; Bridges, 1952).

Durante momentos tempranos (6.500-5.000 años AP) observamos un énfasis muy marcado en la explotación de cormorán en Englefield 1, Bahía Colorada y PZZ-2. Para el período Intermedio (ca. 4.000 años AP) sólo existe registro del sitio PZZ3 donde también prevalecen los cormoranes y en el período Tardío (2.000 años AP al presente) los cormoranes son los más abundantes en PZZ-4 y en Punta Baja, aunque en proporciones distintas (ver Tabla 1). Respecto a estos últimos sitios, es interesante destacar que en Punta Baja (270 \pm 80 años AP) la segunda categoría taxonómica más abundante fue Spheniscus magellanicus (12,7\%), en tanto en PZZ-4 (960 \pm 30 años AP) no se registró esta especie, lo que podría corresponder a la ausencia de colonias durante los momentos de ocupación de PZZ-4. Pese a lo anterior, considerando su baja representación y sólo de individuos adultos en PZZ-2 y PZZ-3, es sugerente suponer que habría sido una caza oportunista.

En definitiva, la explotación y más específicamente las etapas sucesivas que involucran el aprovechamiento alimenticio de recursos avifaunísticos, no presentan mayores variaciones a lo largo de la secuencia de ocupación de la bahía Pizzulic, resaltando el rol de los cormoranes como especie fundamental para la subsistencia de estas poblaciones de cazadores-recolectores marinos que habitaron el seno Otway desde el Holoceno medio hasta época histórica.

En último lugar y, a partir de la discusión generada en este trabajo, surgen algunas interrogantes respecto a la relevancia de recursos de menor porte pero que habrían sido igual de atractivos que los mamíferos marinos para los cazadores-recolectores marinos del seno Otway y que serán evaluados a futuro.

\section{AGRADECIMIENTOS}

Este trabajo fue financiado por el Proyecto FONDECYT №1085329 y cuyos resultados fueron parte de mi tesis de pregrado. Quisiera agradecer a Manuel San Román por permitirme participar en dicho proyecto y ser mi tutor de tesis; a Francisco Cayla por la confección del mapa; a Andrés Garat por la edición de las imágenes; a Cristóbal Palacios por su apoyo con los gráficos; a Jimena Torres y Daniela Villalón por sus aportes a la discusión; y finalmente a los evaluadores anónimos quienes entregaron importantes contribuciones en pos de mejorar el manuscrito.

\section{BIBLIOGRAFÍA}

Barrientos, M. J. (2018). Estrategias de explotación y procesamiento de aves. Cambios y continuidades en las pautas de aprovechamiento a partir de tres yacimientos arqueológicos ubicados en isla Englefield, seno Otway, Patagonia meridional, Chile. Tesis para optar al título de arqueólogo. Universidad SEK.

Baumel, J., \& Witmer, L. (1993). Anatomía. Handbook of Avian Anatomy: Nomina Anatómica Avium. Massachusetts, Estados Unidos: Publications of the Nuttall Ornithological Club.

Binford, L. (1981). Bones: Ancient Men and Modern Myths. New York, Estados Unidos: Academic Press.

Bridges, L. (1952). El último confín de la tierra. Emecé Editores, Buenos Aires.

Cohen, A., \& Serjeantson, D. (1996). A manual for the identification of bird bones from archaeological sites. London, Inglaterra: Archetype Publication Ltd.

Cruz, I. (2001). Los pingüinos como presas durante el Holoceno. Información biológica, fósil y arqueológica para discutir su disponibilidad en el sur de Patagonia. Archaeofauna, 10, 99-112.

Cruz, I. (2005). La representación de partes esqueléticas de aves. Patrones naturales e interpretación arqueológica. Archaeofauna, 14, 69-81.

Cruz, I. (2014). Estudios sobre meteorización de huesos en Patagonia. Revista Chilena de Antropología, 29(1), 89-94.

Cruz, I., \& Savanti, F. (1999). Tafonomía de restos óseos de aves en el sur de Patagonia. Actas del XIII Congreso Nacional de Arqueología Argentina 4: 45-54. Córdoba. Universidad Nacional de Córdoba.

Chapman, A. (2002). El Fin del mundo. Los Selknam de 
Tierra del Fuego. Santiago: Pehuén.

Ede, D. A. (1965). Anatomía de las aves. Zaragoza, España: Editorial Acribia.

Emperaire, J. (2002). Los nómades del mar. Santiago, Chile: LOM Ediciones.

Emperaire, J., \& Laming, A. (1961). Les gisement des iles Englefield et Vivian dans la mer d'Otway, Patagonie australe. Journal de la société des Américanistes, 50, 7-75.

García Moreno, A. (2010). Haciendo humanos a los humanos. Una reflexión crítica sobre la aplicación de las teorías del forrajeo óptimo a las sociedades de cazadoresrecolectores. Revista Atlántica Mediterránea de Prehistoria y Arqueología Social, 12, 25-34.

Estévez, J., \& Gassiot, E. (2002). El cambio en sociedades cazadoras litorales: tres casos comparativos. Revista Atlántica-Mediterránea de Prehistoria y Arqueología Social, 5, 43-85.

GEA-UMAG. (2008). Linea Base fauna para proyecto Southern Star Coal. Grupo de Estudios Ambientales, Universidad de Magallanes, Chile.

Gifford-González, D. P. (1989). Etnographic analogues for interpreting modified bones: Some cases from East Africa. In R. Bonnichsen \& M.H Sorg (Eds.), Bone Modification (pp. 179-246). Universidad de Maine: Center for the study of the first Americans.

Grayson, D. (1984). Quantitative Zooarchaeology. Washington: Academic Press.

Gusinde, M. (1991). Los indios de Tierra del Fuego. Los halakwulup. Argentina: Centro Argentino de Etnología Americana.

Lefèvre, C. (1989a). L' avifaune de Patagonie australe et ses relations avec l' homme au cours des six derniers millenaires (tesis doctoral). Paris, Francia: Université de Paris.

Lefèvre, C. (1989b). Les Oiseaux. En D. Legoupil (Ed.), EthnoArchéologie dans les Archipels de Patagonie: les nomades marins de Punta Baja (pp. 99-113). Paris, Francia: Editions Recherche sur les Civilisations.

Lefèvre, C. (1993-1994). Las aves en los yacimientos del archipiélago de Cabo de Hornos y del Seno Grandi. Anales del Instituto de la Patagonia, 22, 123-136.

Lefèvre, C. (1997a). Seabird fowling in southern Patagonia: a contribution to understanding the nomadic round of the Canoeros indians. International Journal of Osteoarchaeology, 7, 260-270.

Lefèvre, C. (1997b). Les Oiseaux. En D. Legoupil (Ed.), Bahía Colorada (Île d'Englefield) (pp. 59-64). Paris, Francia: Editions Recherche sur les Civilisations.
Lefèvre, C. (2010). Birds in maritime hunter - gatherers subsistence: case studies from Southern Patagonia and the Aleutian Islands. Birds in Archaeology. Proceedings of the $6^{\text {th }}$ Meeting of the ICAZ Bird Working Group in Groningen, 10, 117-230. Groningen Archaeological Studies. Barkhuis Publisher, Groningen.

Lefèvre, C., \& Pasquet, E. (1994). Les modifications postmortem chez les oiseaux: L'exemple de l'avifaune d'Holocène de Patagonie australe. En Outillage peu élaboré en os et en bois de cervidés IV: Taphonomie/ bone modification (Artefacts, 9). Belgique: Editions de Centre d`Etudes et de Documentation Arquéologiques.

Lefèvre, C., \& Laroulandie, V. (2014). Avian Skeletal Part Representation: A Case Study from Offing 2, A Hunter- Gatherer-Fisher Site in the Strait of Magellan (Chile). International Journal of Osteoarchaeology, 24, 256-264.

Legoupil, D. (1997). Bahía Colorada (Île d'Englefield). Les premiers chasseurs de mammifères marins de Patagonie austral. Paris. Francia: Editions Recherche sur les Civilisations.

Legoupil, D. (2000). El sistema socioeconómico de los Nómades del Mar de Skyring-Archipiélago de Patagonia. Anales del Instituto de la Patagonia, 28, 81-120.

Legoupil, D. (2013). Bahía Colorada. Los cazadores de mamíferos marinos tempranos de la isla Englefield (Patagonia austral). Punta Arenas, Chile: Ediciones Universidad de Magallanes.

Legoupil, D., Béarez, P., Lefèvre, C., San Román, M. y Torres, J. (2011). Estrategias de subsistencia de cazadores recolectores de isla Dawson (estrecho de Magallanes) durante la segunda mitad del Holoceno: primeras aproximaciones. Magallania, 39(2):153-164.

Lupo, K., \& Schmitt, D. (2005). Small prey hunting technology and zooarchaeological measures of taxonomic diversity and abundance: Ethnoarchaeological evidence from Central Africa forest foragers. Journal of Anthropological Archaeology, 24, 335-353.

Lyman, R. L. (1994). Quantitative units and terminology in zooarchaeology. American Antiquity, 59(1), 36-71.

Lyman, R. L. (2008). Quantitative Paleozoology. Cambridge Manuals in Archaeology. Oxford, Inglaterra: Cambridge University Press.

Lyman, R. L. (2015). On the variable relationship between NISP and NTAXA in bird remains and in mammal remains. Journal of Archaeological Science, 53, 291-296.

Mameli, L. (2003). La gestión del recurso avifaunístico por las poblaciones canoeras del archipiélago fueguino. Tesis doctoral inédita. Universidad Autónoma de 
Barcelona, Facultad de Letras. Barcelona, España.

Mameli, L., \& Estévez, J. (2004). Etnoarqueología de aves: el ejemplo del extremo sur americano. Treballs d'Etnoarqueologia 5. Madrid, España: Universidad Autónoma de Barcelona y Consejo Superior de Investigaciones Científicas CSIC.

Mengoni, G. L. (1999). Cazadores de guanaco de la Estepa Patagónica. Buenos Aires, Argentina: Sociedad Argentina de Antropología.

Moreno, F., Verdún, E., \& Estévez, J. (2009). Arqueozoología de sociedades cazadoras-recolectoras: algo más que biomasa para estómagos ambulantes. En A. Capparelli, A. Chevalier \& R. Piqué (Eds.), La alimentación en la América precolombina y colonial: una aproximación interdisciplinaria (pp. 9-19). Barcelona, España: Treballs d'Etnoarqueologia.

Muñoz, S., \& Savanti, F. (1998). Observaciones tafonómicas sobre restos avifaunísticos de la costa noreste de Tierra del Fuego. Actas y Memorias del XI Congreso Nacional de Arqueología Argentina ( $8^{\mathrm{a}}$ parte), Revista del Museo de Historia Natural de San Rafael (Mendoza), XX (1/2), 107-121.

Orquera, L., \& Piana, E. (1999). Arqueología de la región del canal Beagle (Tierra del Fuego, República Argentina). Buenos Aires, Argentina: Sociedad Argentina de Antropología.

Orquera, L., \& Piana, E. (2015). La vida social y material de los Yámana. Monte Olivia. Ushuaia. Argentina.

Piana, E., Vázquez, M., \& Tivoli, A. (2007). Dieta y algo más. Animales pequeños y variabilidad en el comportamiento humano en el canal Beagle. En F. Morello, M. Martinic, A. Prieto \& G. Bahamondes (Eds.), Levantando piedras, desenterrando huesos...y develando arcanos (pp. 39-50). Punta Arenas, Chile: Ediciones CEQUA.

Reitz, E., \& Wing, E. (2008). Zooarchaeology. Cambridge Manuals in Archaeology, segunda edición. Cambridge, Inglaterra: Cambridge University Press.

San Román, M. (2005). Nuevos hallazgos de sitios de cazadores recolectores marinos tempranos en la isla Englefield, mar de Otway. Magallania, 33(2), 173-176.

San Román, M. (2013). Sitios arqueológicos de isla Englefield, mar de Otway: nuevas evidencias de discontinuidad cultural en el proceso de poblamiento marítimo de Patagonia meridional. En F. Zangrando, R. Barberena, A. Gil, G. Neme, L. Giardina, L. Luna, C. Otaola, L. Paulides, L. Salgán \& A. Tivoli (Eds.), Tendencias Teórico-Metodológicas y Casos de Estudio en la Arqueología de la Patagonia (pp. 523-534). Buenos
Aires, Argentina: Museo de Historia Natural de San Rafael, Mendoza; Sociedad de Antropología Argentina e Instituto Nacional de Antropología y Pensamiento Latinoamericano.

San Román, M. (2016). Stratégies économiques et sociales des chasseurs marins de Patagonie: Archéozoologie des sites anciens du détroit de Magellanet des mers intérieures (Chili) (thèse de doctorat). Université de Paris I Panthéon-Sorbonne, Francia.

San Román, M., Reyes, O., Morello, F., \& Torres, J. (2016). Archaeology of maritime Hunter-Gatherers from Southernmost Patagonia, South America: discussing timing, changes and cultural traditions during the Holocene. In H. Bjartmann, H. Mjelva, S. Fretheim, E. Piana, B. Skar, A. Tivoli \& F. Zangrando (Eds.), Marine Ventures: Archaeological Perspectives on Human-Sea Relations (pp. 157-174). Bristol: Equinox Publishing.

Savanti, F. (1994). Las Aves en la dieta de los cazadores recolectores terrestres de la costa fueguina (tesis de licenciatura). Buenos Aires, Argentina: Facultad de Filosofía y Letras, Universidad de Buenos Aires.

Schiavini, A. (1993). Los lobos marinos como recurso para cazadores-recolectores marinos: El caso de Tierra del Fuego. Latin American Antiquity, 4(4), 346-366.

Serjeantson, D. (2009). Birds. Cambridge Manuals in Archaeology. Cambridge: Cambridge University Press.

Tivoli, A. (2010a). Las aves en la organización socioeconómica de cazadores-recolectores-pescadores del extremo sur sudamericano (tesis doctoral inédita). Buenos Aires, Argentina: Facultad de Filosofía y Letras, Universidad de Buenos Aires.

Tivoli, A. (2010b). Exploitation of bird resources among prehistoric sea-nomad societies of the Beagle Channel region, southern South America. Before Farming, 2, $1-12$

Tivoli, A. (2012). ¿Intensificación? en el aprovechamiento de aves entre los cazadores recolectores pescadores de la región del canal Beagle. Archeofauna, 21, 121-137.

Tivoli, A. (2014). Las aves en la alimentación y tecnología de los pueblos originarios de la región del canal Beagle. En J. Oría \& A. Tivoli (Eds.), Cazadores de mar y tierra. Estudios recientes en arqueología fueguina (pp. 85107). Ushuaia, Argentina: Editora Cultural Tierra del Fuego y Museo del Fin del Mundo.

Tivoli, A., \& Zangrando, F. (2011). Subsistence variations and landscape use among maritime hunter-gatherers. A zooarchaeological analysis from the Beagle Channel (Tierra del Fuego, Argentina). Journal of Archaeological Science, 38, 1148-1156. 
Torres, J., Mahé, K., Dufour, J. L., Béarez, P., \& San Román, M. (2020). Characterizing seasonal fishing patterns and growth dynamics during the Middle and Late Holocene in the Strait of Magellan (Chilean Patagonia): Sclerochronological analysis of tadpole codling (Salilota australis) vertebrae. The Journal of Island and Coastal Archaeology. https://doi.org/10.1080/ 15564894.2020.1755393.

Vega, C. (2009). Cuando el cielo se oscurece (Samán arkachoé). Historia de vida, testimonio alakalufe de Alberto Achacaz Walakial. Punta Arenas: Editorial Atelí.

Waselkov, G. (1987). Shellish gathering and shell midden archaeology. In M. Schiffer (Ed.), Advances in Archaeological Method and Theory 10, (pp. 93-210). San Diego, Estados Unidos: Academic Press.

Zangrando, F. (2009). Historia Evolutiva y Subsistencia de Cazadores, Recolectores y Pescadores Marítimos de Tierra del Fuego: una aproximación zooarqueológica. Buenos Aires, Argentina: Sociedad Argentina de Antropología.

Zangrando, F., \& Tivoli, A. (2015). Human use of birds and fish in marine settings of southern Patagonia and Tierra del Fuego in the Holocene: A first macro-regional approach. Quaternary International, 373, 82-95. 